\title{
Tempo de migração dos macrófagos em matrinxã, Brycon amazonicus, por meio da técnica de inoculação de leveduras Saccharomyces cerevisiae
}

\author{
Danielle de Carla DIAS ${ }^{1}$, Leonardo TACHIBANA², Robson SERIANI ${ }^{3}$, Antenor Aguiar SANTOS ${ }^{4}$, Maria \\ José Tavares RANZANI-PAIVA ${ }^{5}$, Elizabeth ROMAGOSA ${ }^{6}$
}

\begin{abstract}
RESUMO
$\mathrm{Na}$ aquicultura são utilizados análises da ativação e incremento da migração de macrófagos, com intuito de verificar a capacidade imunológica inespecífica dos peixes frente a um desafio. Neste sentido, o objetivo deste estudo foi determinar o tempo de migraçáo de monócitos/macrófagos para a cavidade peritoneal em matrinxã, Brycon amazonicus, por meio da técnica de inoculação de leveduras Saccharomyces cerevisiae, e verificar as possíveis alterações dos parâmetros hematológicos após o estímulo. Foram utilizados 30 matrinxãs com peso médio de 101,55 $\pm 24,50 \mathrm{~g}$ e comprimento médio de 19,75 $\pm 1,72 \mathrm{~cm}$. Os tempos de inoculação utilizados foram 2, 4, 8 e 12 horas, sendo utilizados 6 animais por tempo. Após os períodos de incubaçáo (2, 4,8 e 12 horas), os exemplares foram anestesiados e alíquotas de sangue foram coletadas por punção do vaso caudal, para a análise: número total de células, contagem diferencial e total dos leucócitos e contagem total de trombócitos, hematócrito, taxa de hemoglobina e índices hematimétricos (VCM, HCM e CHCM). Os resultados mostram que a capacidade fagocítica do macrófago não apresentou diferenças significativas entre os tempos experimentais. Com relaçáo ao índice fagocítico, o tempo de 2 horas representa o tempo em que os macrófagos fagocitaram maior número de leveduras com diferenças significativas em relação aos outros tempos experimentais, indicando que este tempo ( 2 horas) de incubação foi suficiente para a migração e ativação máxima dos macrófagos da cavidade peritoneal, da espécie estudada. Os valores do número de eritrócitos apresentaram diferenças entre os tempos de incubação. Entretanto, os valores dos outros parâmetros hematológicos não apresentaram diferenças significativas.
\end{abstract}

PALAVRAS-CHAVE: Fagocitose, Inoculação, Hematologia

\section{Macrophagic migration time in matrinxã, Brycon amazonicus, through inoculation of yeast, Saccharomyces cerevisiae, technique}

\begin{abstract}
In aquaculture, analysis of activation and increased macrophages migration are used in order to verify the ability of the nonspecific immune fish exposed to a challenge. This study aimed to determine the time of macrophages migration in matrinxâ, Brycon amazonicus, through the technique of yeast Saccharomyces cerevisiae inoculation, verifying possible changes in hematological parameters. Thirty animals with average weight of $101.55 \pm 24.50 \mathrm{~g}$ and average length of $19.75 \pm 1.72 \mathrm{~cm}$ were employed. The experimental inoculation periods were 2, 4, 8 and 12 hours. Thereafter, animals were anesthetized and blood was withdrawn through a caudal puncture for the determination of total erythrocytes number, differential and total leukocyte counts and total thrombocytes count, hematocrit, hemoglobin concentration and calculation of the erythrocytes index. The results for the phagocytic capacity were not significantly different between experimental periods. In the phagocytic index, the period of 2 hours presented the highest rate of phagocytized cells, indicating that 2 hours of incubation was sufficient for the macrophages migration in B. amazonicus. The number of erythrocyte was the only parameter that presented significant difference among periods.
\end{abstract}

KEYWORDS: Phagocytosis, Inoculation, Hematology

\footnotetext{
1 Centro de Aquicultura da UNESP - CAUNESP. daniellebio2004@yahoo.com.br

2 Instituto de Pesca - SP. leotachibana@apta.sp.gov.br

3 Instituto de Pesca - SP. robsonseriani@yahoo.com.br

${ }^{4}$ Universidade Adventista - UNASP. antenor.aguiar@terra.com.br

${ }^{5}$ Instituto de Pesca - SP. mase@pesca.sp.gov.br

${ }^{6}$ Instituto de Pesca - SP. eromagosa@pesca.sp.gov.br
} 


\section{INTRODUÇÃO}

$\mathrm{Na}$ aquicultura estấo sendo utilizados testes para analisar a ativação e o incremento da migração de macrófagos, com intuito de verificar a capacidade imunológica inespecífica dos animais frente a um desafio, permitindo avaliar a migração dos macrófagos até a cavidade celomática na qual se pode estimar a capacidade e índice fagocítico dos macrófagos. Esta metodologia descrita por Silva et al. $(2002 ; 2005)$ foi utilizada para determinar a capacidade fagocítica e o índice fagocítico de macrófagos da cavidade celomática em Notothenia neglecta e $N$. coriiceps espécies de peixes antárticos. Este método também tem sido utilizado para Centropomus parallelus, espécie marinha tropical (Ranzani-Paiva et al. 2008) e para anfíbio, Lithobates catesbeianus (Dias et al. 2009). Essa técnica permite avaliar capacidade fagocítica de macrófagos através da inoculação e contagem das leveduras fagocitadas. Entretanto, para a realizaçâo desse estudo é necessário conhecer o tempo de incubação de leveduras que representa o tempo de maior atividade fagocítica dos macrófagos. Esse tempo de incubaçáo pode variar entre as diferentes espécies de peixes.

Os monócitos-macrófagos são fundamentais na defesa dos diferentes organismos evidenciado em vertebrados inferiores e superiores. Assim, neste estudo da atividade fagocítica foi eleito o macrófago, por representar a principal célula do sistema imune dos vertebrados. Em praticamente todas as reaçóes imunes contra doenças e agressōes em peixes os macrófagos atuam (Zelikoff et al. 1991) envolvendo-se no processo de fagocitose e na destruição de material exógeno, interligando o sistema imune inespecífico ao específico. Este tipo celular pode ser isolado do sangue (monócitos), de órgáo linfo-mioelóides (baço, timo e rim cefálico) ou da cavidade peritoneal (Vallejo et al. 1992; Shoemaker et al. 1997). A principal característica dos macrófagos é a capacidade de ingerir material estranho, inerte e antigênico, assim como restos celulares da resposta inflamatória e de outros processos degenerativos.

O padrão da capacidade e dos índices fagocíticos podem ser utilizados como indicadores da homeostase ou de alteraçốes que causem dano aos peixes (Pulsford et al. 1984; Blazer 1991). Com base no exposto, bioensaios de induçăo do processo inflamatório e conseqüente estímulo à atividade macrofágica vem assumindo importante papel para a compreensão, não só da biologia dos peixes, mas também das inter-relaçôes ambientais (Silva et al. 1998).

O objetivo deste estudo foi determinar o tempo de maior atividade fagocítica dos macrófagos da cavidade celomática em matrinxấ, Brycon amazonicus, por meio da técnica de inoculação de leveduras, Saccharomyces cerevisiae e verificar possíveis alteraçóes hematológicas após a inoculação.

\section{MATERIAL E MÉTODOS}

O experimento foi realizado no Pólo Regional do Vale do Ribeira APTA -SAA, em Pariquera-Açu SP/ Brasil. Foram utilizados 30 matrinxãs com peso médio de $101,55 \pm 24,50$ g e comprimento médio de $19,75 \pm$ $1,72 \mathrm{~cm}$. Os tempos de inoculaçáo utilizados foram 2, 4, 8 e 12 horas, sendo utilizados 6 peixes por tempo, que eram colocados separadamente em caixas de $500 \mathrm{~L}$. Também foram utilizados 6 exemplares (controle) que nâo receberam nenhum tipo de substância intracelomático. Os animais foram anestesiados com óleo de cravo na concentração de $80 \mathrm{mg} \mathrm{L}^{-1}$ (Delbon 2006), em seguida, injetados intracelomático 3 $\mathrm{mL}$ de solução de levedura na concentração de 8.000 células $\mathrm{mm}^{-3} \mathrm{de}$ Saccharomyces cerevisiae. Após os períodos de inoculação, os animais foram anestesiados novamente, e retirada alíquotas de sangue por punção do vaso caudal, com auxílio de seringas descartáveis, heparinizadas utilizadas nas determinaçóes do número total de células, em câmara de Neubauer, utilizando-se soluçáo de Hayen como diluente; contagem diferencial e total dos leucócitos e contagem de trombócitos pelo método indireto (Hrube e Smith 1998) em extensōes sangüíneas coradas pelo May-Grünwald-Giemsa, segundo Rosenfeld (1947); hematócrito, pelo método do microhematócrito, segundo Goldenfarb et al. (1971); taxa de hemoglobina, pelo método da cianometahemoglobina (Collier 1944); calculados os índices hematimétricos VCM (volume corpuscular médio), HCM (hemoglobina corpuscular média) e CHCM (concentração de hemoglobina corpuscular média).

Após a coleta de sangue, os peixes foram sacrificados por sedação profunda (Delbon 2006) e a cavidade celomática foi delicadamente lavada com 3,0 mL de solução de PBS (Phosphate Buffered Saline). A seguir, o líquido contendo as células inflamatórias (macrófagos) foi aspirado com pipeta Pasteur. O lavado foi centrifugado a $1500 \mathrm{rpm}(251.5 \mathrm{x}$ g) por 5 min e o sobrenadante desprezado. O restante do lavado foi utilizado para a determinação da capacidade fagocítica (CF) e do índice fagocítico (IF) de macrófagos nos diferentes tempos, através de microscopia de contraste de fase, segundo metodologia de Silva et al. $(2002 ; 2005)$ e Ranzani-Paiva $e t$ al. (2008). As fórmulas utilizadas foram: $\mathrm{CF}=\mathrm{n}^{\circ}$ de macrófagos fagocitando / 100 e IF $=\mathrm{n}^{\circ}$ total de leveduras no interior dos macrófagos / número de macrófagos fagocitando (Silva et al. 2002 e 2005; Ranzani-Paiva et al. 2008).

Para verificar as diferenças entre os diferentes tempos de inoculação, foi realizada a análise de variância (Anova) seguida pelo teste de Tukey (Zar 1996).

\section{RESULTADOS E DISCUSSÃO}

A Capacidade Fagocítica (CF) e o Índice Fagocítico (IF) dos macrófagos nos diferentes tempos de inoculação estão apresentados nas Figuras 1 e 2 . Pode-se observar que a CF não apresentou diferença significativa $(\mathrm{p}>0,05)$ entre os tempos experimentais. Com relaçáo ao IF, o tempo de 2 horas mostrou maior número de células fagocitadas apresentando diferenças significativas quando comparado estatisticamente aos tempos experimentais. Neste estudo os resultados indicam que 2 horas mostrou ser suficiente para promover a migraçáo e ativaçáo máxima dos macrófagos da cavidade celomática para remover o agente agressor em Brycon amazonicus. Após duas horas de inoculação os valores do índice fagocítico dos macrófagos da cavidade celomática de B. amazonicus diminuem significantemente. Essa diminuição pode estar relacionada com a atuação do sistema imune específico do peixe, semelhante aos resultados observados em Prochilodus scrofa por Jensch-Junior (2002).

Segundo Mulero et al. (1998) e Jensch-Junior (2002) as mudanças encontradas na resposta imune são pontuais e temporária, cada atividade alcança o seu máximo em diferentes tempos e sugerem que a resposta imune náo é unitária. Além do mais, sabe-se que o tempo de maior ativaçấo na remoção de agentes estranhos pode variar de espécie para espécie, do tipo de imunoestimulante utilizado, temperatura, estresse, alimentação etc. Segundo Ranzani-Paiva et al. (2006) para o peixe estuarino, Centropomus parallelus o tempo de maior atividade fagocítica (Capacidade e índice fagocíticos) foi de $8 \mathrm{~h}$, já para râ-touro Lithobates catesbeianus (Rana catesbeiana) o tempo observado foi de $2 \mathrm{~h}$ (Dias et al. 2009).

\section{CAPACIDADE FAGOCIITICA}



Figura 1 - Valores médios percentuais da capacidade fagocítica de matrinxã, Brycon amazonicus nos diferentes tempos de incubação de leveduras (Médias seguidas de mesma letra não diferem significativamente). 


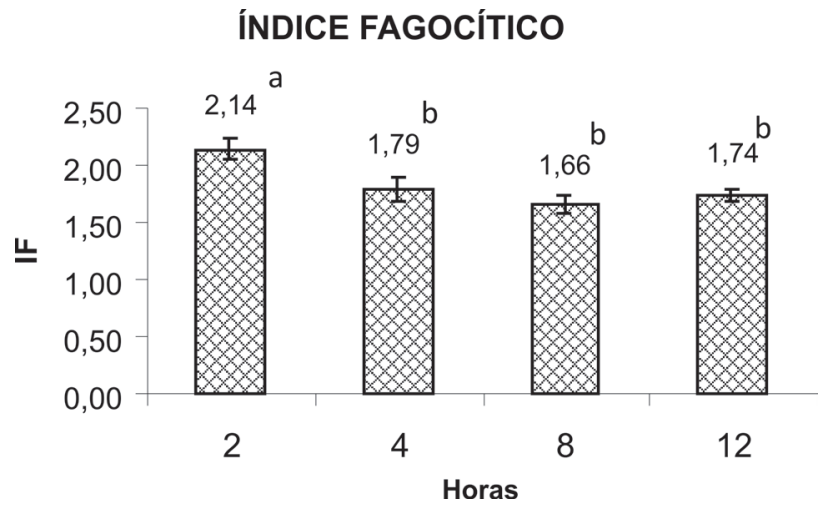

Figura 2 - Valores médios do índice fagocítico de matrinxã Brycon amazonicus nos diferentes tempos de incubação de leveduras (Médias seguidas de mesma letra não diferem significativamente)

Avaliando-se os resultados obtidos por meio das análises estatísticas para os parâmetros hematológicos foi observado que houve diferença significativa $(\mathrm{p}<0,05)$ somente para os valores do número de eritrócitos onde se observou valores estatisticamente elevados no tempo 2 horas em relação ao tempo de 8 horas, no entanto os valores do grupo controle foram estatisticamente inferiores aos valores obtidos nos tempos de 4,8 e 12 horas após a inoculação (Tabela 1). Entretanto os outros parâmetros hematológicos não apresentaram o mesmo comportamento $(p>0,05)$ (Tabela 2 e 3). Mesmo os animais sendo anestesiados durante o manejo para inoculaçáo de soluçáo de levedura, este aumento no valor de eritrócitos pode estar relacionado ao estresse de manejo sofrido (Chagas e Val 2003), pois os valores aumentaram progressivamente conforme o tempo de espera de inoculação.
$\mathrm{Na}$ tabela 2, pode-se visualizar que os valores de trombócitos, células responsáveis pela hemostasia e possível mecanismos de defesa do organismo como demonstrado por Matushima e Mariano (1996), apresentaram valores diminuídos conforme o tempo de inoculação, não diferindo estatisticamente $(\mathrm{p}=0,22)$. O teste de Pearson mostrou correlação inversamente proporcional, com diminuição do número de trombócitos em relação aos valores de leucócitos totais ao longo do tempo experimental. Tal fato denota que outras células de defesa como os linfócitos, neutrófilos e monócitos provavelmente estejam envolvidos mais acentuadamente na resposta imune do que os trombócitos. Além disso, segundo Sopinska (1985), o aumento dos valores dos leucócitos como, por exemplo, dos monócitos, mesmo que a elevação seja de forma sutil, reflete a intensificaçáo do mecanismo de defesa celular.

Tabela 2 -Valores médios e erro padrão da média (EPM) do número absoluto de trombócitos de matrinxã, Brycon amazonicus nos diferentes tempos de inoculação de leveduras

\begin{tabular}{lc}
\hline Tratamentos & Trombócitos $(\mu \mathrm{L})$ \\
\hline Controle & $13.243,89 \pm 4.260,44$ \\
$2 \mathrm{~h}$ & $11.555,10 \pm 1.878,95$ \\
$\mathrm{~h} \mathrm{~h}$ & $13.493,88 \pm 3260,27$ \\
$8 \mathrm{~h}$ & $4.544,42 \pm 1.015,80$ \\
$12 \mathrm{~h}$ & $9.534,07 \pm 3.794,34$ \\
\hline
\end{tabular}

Apesar dos valores dos leucócitos não mostrarem diferenças significantes nos diferentes tempos de inoculação, vale ressaltar que os tempos 8 e 12 horas de inoculação foram os tempos de maior circulação leucocitária, especialmente dos neutrófilos e monócitos. Considerando que o tempo de 12 horas de inoculação foi o tempo máximo avaliado neste estudo, se faz necessário determinar o pool de leucócitos circulante após o tempo de 12

Tabela 1 - Valores médios e erro padrão da média (EPM) dos parâmetros hematológicos de matrinxã Brycon amazonicus nos diferentes tempos de inoculação de leveduras

\begin{tabular}{lcccccc}
\hline \multirow{2}{*}{ Tempo } & $\mathrm{Ht}$ & $\mathrm{Hb}$ & $\mathrm{RBC}$ & $\mathrm{VCM}$ & $\mathrm{HCM}$ & $\mathrm{CHCM}$ \\
\cline { 2 - 7 } & $\mathrm{X} \pm \mathrm{EPM}$ & $\mathrm{X} \pm$ EPM & $\mathrm{X} \pm$ EPM & $\mathrm{X} \pm$ EPM & X \pm EPM & X \pm EPM \\
\hline Controle & $38,83 \pm 1,33$ & $10,62 \pm 0,44$ & $289,5 \pm 8,89^{\mathrm{a}}$ & $134,57 \pm 4,27$ & $36,99 \pm 1,94$ & $27,42 \pm 0,89$ \\
2h & $42,17 \pm 1,49$ & $12,46 \pm 0,28$ & $343,92 \pm 13,31^{\mathrm{a}}$ & $124,75 \pm 8,23$ & $36,78 \pm 1,91$ & $29,72 \pm 0,73$ \\
4h & $40,83 \pm 1,83$ & $11,46 \pm 0,55$ & $327,00 \pm 9,64^{\text {ab }}$ & $124,67 \pm 3,28$ & $35,02 \pm 1,22$ & $28,08 \pm 0,57$ \\
8h & $38,17 \pm 0,54$ & $10,92 \pm 0,32$ & $330,00 \pm 1,41^{\text {b }}$ & $115,67 \pm 1,72$ & $33,06 \pm 0,83$ & $28,63 \pm 0,82$ \\
12h & $41,83 \pm 1,16$ & $11,58 \pm 0,30$ & $329,75 \pm 18,75^{\text {ab }}$ & $129,31 \pm 5,59$ & $35,73 \pm 1,35$ & $27,71 \pm 0,48$ \\
\hline
\end{tabular}

$\mathrm{Ht}=$ hematócrito $(\%) ; \mathrm{Hb}=$ taxa de hemoglobina $\left(\mathrm{g} \mathrm{dL}^{-1}\right) ; \mathrm{RBC}=$ número de eritrócitos $\left(10^{4} \mathrm{~mm}^{-3}\right) ; \mathrm{VCM}=$ volume corpuscular médio (fL); $\mathrm{HCM}$ $=$ hemoglobina Corpuscular média $(\mathrm{pg} / \mathrm{cel}) ; \mathrm{CHCM}=$ concentração de hemoglobina corpuscular média $\left(\mathrm{g} \mathrm{dL}^{-1}\right)$; Letras iguais na coluna diferem significativamente segundo teste de Tukey $(\mathrm{P}<0,05)$

Tabela 3 - Valores médios e erro padrão da média (EPM) dos leucócitos de matrinxã, Brycon amazonicus nos diferentes tempos de inoculação de leveduras

\begin{tabular}{lcccccc}
\hline \multirow{2}{*}{ Tratamento } & Leucócitos Totais & Linfócitos & Neutrófilos & \multicolumn{2}{c}{ Basófilos } & \multicolumn{2}{c}{ Eosinófilos } & Monócitos \\
\cline { 2 - 7 } & $(\mu \mathrm{L})$ & $(\mu \mathrm{L})$ & $(\mu \mathrm{L})$ & $(\mu \mathrm{L})$ & $(\mu \mathrm{L})$ & $(\mu \mathrm{L})$ \\
\hline Controle & $6.810,54 \pm 1.739,45$ & $3.721,99 \pm 1.100,27$ & $2.499,04 \pm 700,03$ & $33,60 \pm 23,84$ & $18,36 \pm 18,36$ & $552,24 \pm 177,46$ \\
$2 \mathrm{~h}$ & $13.031,06 \pm 1.699,09$ & $4.394,85 \pm 660,44$ & $7.343,57 \pm 1.286,37$ & 0,00 & 0,00 & $1.292,64 \pm 208,53$ \\
\hline $\mathrm{h}$ & $10.291,51 \pm 2.563,88$ & $4.874,27 \pm 1.636,53$ & $5.161,21 \pm 1.134,24$ & 0,00 & 0,00 & $205,00 \pm 64,75$ \\
\hline $\mathrm{h}$ & $13.930,10 \pm 2.175,87$ & $6.497,37 \pm 965,81$ & $6.754,98 \pm 1.167,20$ & 0,00 & $8,70 \pm 8,70$ & $669,05 \pm 175,23$ \\
$12 \mathrm{~h}$ & $14.697,18 \pm 3806,62$ & $5.240,97 \pm 1.930,21$ & $7.673,24 \pm 2.419,11$ & 0,00 & 0,00 & $1.782,98 \pm 865,03$ \\
\hline
\end{tabular}


horas de inoculação para que se possa ter uma cinética completa do pool circulante de leucócitos frente a instímulo e verificar se haverá correlação positiva com a atividade fagocítica dos macrófagos da cavidade celomática nos mesmos tempos.

O aumento do número dos eritrócitos com diferença significativa correlacionou com as alteraçôes (que não foram significativas) do número dos monócitos e neutrófilos. Nota-se que o aumento do número de ambas as células e também na concentraçáo de hemoglobina pode estar associado com a maior demanda de energia/oxigênio pelo organismo, o que normalmente ocorre em situaçôes de estresse agudo, neste caso, representado pela inoculação de leveduras. Neste sentido a elevação dos valores do número de eritrócitos, pode ser visto como uma resposta no aumento da eficiência para o transporte de oxigênio, uma vez que este contribui e influencia diretamente na disponibilidade de energia empregada nos processos imunológicos.

\section{CONCLUSÃO}

O tempo de $2 \mathrm{~h}$ foi o melhor para o estudo da migração de macrófagos para matrinxã, Brycon amazonicus.

\section{BIBLIOGRAFIA CITADA}

Blazer, V.S. 1991. Piscine macrophage function and nutritional influences: A review. Journal of Aquatic Animal Health, 3: 77-86.

Chagas, E.C.; Val, A.L. 2003. Efeito da vitamina C no ganho de peso e em parâmetros hematológicos de tambaqui. Pesquisa Agropecuária Brasileira, 38 (3): 397-402.

Collier, H.B. 1944. The standardization of blood hemoglobin determinations. Canadian Medical Assesment Journal, 50: 550-552.

Delbon, M.C. 2006. Action of benzocaine and clove oil on physiological parameters of tilapia Oreochromis niloticus. Dissertação de Mestrado em Aqüicultura, Universidade Estadual Paulista - UNESP, Campus de Jaboticabal, SP. 91 pp... Disponível em: http://www.caunesp.unesp.br/pg/trabalhos_ dissertacoes_autor.php

Dias, D.C.; De Stéfani, M.V.; Ferreira, C.M.; França, F.M.; Ranzani-Paiva, M.J.T., Santos, A.A. 2009. Haematologic and immunologic parameters of bullfrogs, Lithobates catesbeianus, fed probiotics. Aquaculture Research, 40: 1-8.

Goldenfarb, P.B.; Bowyer, F.P.; Hall, E.; Brosious, E. 1971. Reproducibility in the hematology laboratory: the microhematocrit determination. American Journal of Clinical Pathology, 56: 35-39.

Hrube, T.C.; Smith, S.A. 1998. Hematology of fish, p. 11201125. In: Feldman, B.F.; Zinkl, J.G.; Jain, N.C. (Ed.). Schalm's Veterinary Hematology. 5th ed. Blackburg: Wiley-Blackwell.

Jensch-Junior, B.E. 2002. Estudo da fagocitose in vivo e in vitro de macrófagos do curimbatá Prochilodus scrofa (Steindachner, 1881). Dissertação (Mestrado). Instituto de Ciências Biomédicas da Universidade de São Paulo - USP. 91 pp.

Matushima, E.R.; Mariano, M. 1996. Kinetics of the inflammatory reaction induced by carrageenin in the swinbladder of Oreochromis niloticus (Nile tilapia). Brazilian Journal of Veterinary Animal Science, 33(1): 5-10.
Mulero, V; Esteban, M.A; Meseguer, J. 1998. Effects of in vitro addition of exogenous vitamins $\mathrm{C}$ and $\mathrm{E}$ on gilthead seabream (Sparus aurata L.) phagocytes. Veterinary Immunology and Immunopathology, 66: 185-199.

Pulsford, A. 1984. Preliminary studies on tripanosomes from the dogfish, Scyliarhinus canicula L. Journal of Fish Biology, 6: 671682.

Ranzani-Paiva, M.J.T.; Santos, A.A.; Dias, D.C.; Seriani, R.; Egami, M. 2008. Hematological and phagocytic response of fat snook, Centropomus parallelus, reared in net cages, before and after inoculation with Sacharomyces ceresivisiae. Bioikos, 22: 29-35.

Rosenfeld, G. 1947. Dye panchromic for hematology and cytology clinic. Component of the new constitution and May Grünwald Giemsa stain fast. Memórias do Instituto Butantã, 20: 329-334.

Shoemaker, C.A.; Klesius, P.H.; Plumb, J.A. 1997. Killing of Edwardsiella ictaluri by macrophages from channel catfish immune and susceptible to enteric septicemia of catfish. Veterinary Immunology and Immunopathology, 58: 181-190.

Silva, J.R.M.C.; Hernandez-Blazquez, F.J.; Barbieri, R.L. 1998. Induced inflammatory response in the Antartic fish Notothenia neglecta. Polar Biology, 20: 206-212.

Silva, J.R.M.C.; Porto-Neto, L.R.; Borges J.C.S.; Jensch-Junior B.E. 2005. Germicide capacity of macrophages in the Antartic fish Notothenia coriiceps (Richardson, 1844) at $0^{\circ} \mathrm{C}$. Polar Biology, 28(4): 326-328.

Silva, J.R.M.C.; Staines, N.A.; Hernandez-Blazquez, F.J.; PortoNeto, L.R.; Borges J.C.S. 2002. Phagocytosis and giant cell formation at $0^{\circ} \mathrm{C}$ by macrophage of Notothenia coriiceps. Journal of Fish Biology, 60: 466-478.

Sopinska, A. 1985. Effects physiological factors, stress, and disease on hematologic parameters of carp, with a particular reference to the leukocyte patterns.III. Changes in blood accompanying branchionecrosis and bothriocephalosis. Acta Ichthyologica et Piscatoria, 15: 141-165.

Vallejo, A.N.; Miller, N.W.; Clem, L.W. 1992 Antigen processing and presentation in teleost immune responses. In: Faisal, M.; Hetrick, F.M. (Ed.) Annual Review Fish Disease, 2:73-89.

Zar, J.H. 1996 Biostatistical Analysis. $3^{\text {rd. }}$ Edition, Prentice-Hall, Inc., Upper Saddle River, New Jersey, USA. 662 pp.

Zelikoff, J.T.; Enami, N.A.; Bowser, D.; Squibb, S.; Frenel, K. 1991. Development of fish peritoneal macrophages as a model of higher vertebrates in immunotoxicological studies. 1. Characterization of trout macrophages morphological, functional and biochemical properties. Fundamental Applied Toxicology, 90: 17-26.

Recebido em 03/08/2010

Aceito em 14/08/2010 